\title{
Quantitative Literacy: A Tool for Survival
}

\section{Gizem Karaali}

Pomona College, gizem.karaali@pomona.edu

\section{Recommended Citation}

Karaali, Gizem. "Quantitative Literacy: A Tool for Survival." Numeracy 13, Iss. 2 (2020): Article 5. DOI: https://doi.org/10.5038/1936-4660.13.2.1370 


\title{
Quantitative Literacy: A Tool for Survival
}

\author{
Abstract \\ In the context of a global pandemic, the need for quantitative literacy has become more urgent. QL and \\ QL-adjacent habits of mind, such as awareness of the limitations of data and modeling, are vital tools of \\ survival that can help people understand today's fast-changing world and make decisions about next \\ actions, in particular in relation to the ongoing protests supporting the \#BlackLivesMatter movement. QL \\ does not provide a final answer to most human questions, but it can be an invaluable guide for each \\ individual decision maker.

\section{Keywords} \\ COVID-19, modeling, quantitative literacy \\ Creative Commons License \\ (c) (i) (8) \\ This work is licensed under a Creative Commons Attribution-Noncommercial 4.0 License

\section{Cover Page Footnote} \\ Gizem Karaali completed her undergraduate studies at Boğaziçi University, Istanbul, Turkey. After \\ receiving her Ph.D. in Mathematics from the University of California Berkeley, she taught at the University \\ of California Santa Barbara for two years. She is currently a professor of mathematics at Pomona College \\ where she enjoys teaching a wide variety of courses and working with many interesting people. Her \\ scholarly interests include humanistic mathematics, pedagogy, and quantitative literacy, as well as social \\ justice implications of mathematics and mathematics education.
}


In the July 2018 issue of Numeracy, Dr. Gail Mellow penned an editorial titled "Quantitative Literacy: Now More Than Ever." Referring back to the inaugural issue of the journal, and the article "Evolution of Numeracy and the National Numeracy Network" therein by Bernard Madison and Lynn Arthur Steen (2008), Mellow wrote:

Your work, to provide "tools for survival," has never been more important. We live in a precarious time. Science is ridiculed, facts are dismissed as "fake news," and basic foundations of our democracy are being challenged. [Quantitative literacy] skills are essential for every role in our society - consumer, citizen, student, laborer, manager, or entrepreneur - to make sense of our increasingly complex world.

Two years later, these words still resonate. In the context of a worldwide pandemic accompanied, at least in the case of the United States, by widespread social and political unrest, the phrase "tools of survival" becomes even more literal.

Every spring, for the last few years, I have taught a mathematics course for liberal arts students called Math, Philosophy, and the Real World inspired by Professor Judith Grabiner's course of the same name. After auditing her version of the course, reading her article (Grabiner 2011) about teaching liberal arts mathematics courses, and chatting with her about the issues through the years, I have developed my course in four modules. The first module is on uncertainty and chance, and it revolves around basic notions of combinatorics, probability, and statistics. But more emphatically, this is where I go all in for quantitative literacy (QL). We use several chapters of Jeff Bennett's Math for Life (Bennett 2012) as a starting point for our discussion of the topic. For many of my students, this is their first and only formal engagement with the concept of quantitative literacy.

This spring, in response to the COVID-19 pandemic, my institution moved to remote learning. This happened sometime in mid-March, and though we had already completed our QL module, many of my students kept coming back to some of our class discussions on the relevance and urgency of QL. ${ }^{1}$

One of the first things many of us noted was the difficulty many people (including ourselves) were having with the idea of exponential growth. Most epidemiological models of the onset of a new disease start off exponentially, but exponential growth can be hard to comprehend. This seems to have been one of the major shortcomings of many public responses to the pandemic. Though now, with 20/20 hindsight, we can say that there were enough warning signs from the beginning, that far too many dismissed the possibility of impending disaster. Our political leadership was basically in the land of wishful thinking, and those who were sending the warning signs were ignored by most of the "informed public." I consider myself in this latter group, and I am embarrassed to admit that it took me

\footnotetext{
${ }^{1}$ In her perspective piece in this issue of Numeracy, Jessica Ancker (2020) suggests viewing this moment as a teaching opportunity. Also see Piercey (2020).
} 
a while to accept that there was a growing problem. Even when we knew the disease was not under control, most of us continued our daily lives. Those who had family and business relations in China began stocking up, but almost everyone else around me continued to do daily chores, plan summer vacations, write talks for upcoming conferences, and focus on the next week's classes until the numbers decided to do their thing and show us what was going on.

On June 7, 2020, as I write this paragraph, the CDC COVID Data Tracker shows a linear graph of the total number of cases in the United States from May 8, 2020 , to June $7,2020 .^{2}$ One might hope that we are at a section of the logistic curve where we will soon start trending concavely down, and things are looking up. As the country opens up more and more, however, and as people gather in large groups to enjoy the summer or to protest racist police practices, this linear trend may only be a temporary lull. Time will tell, of course.

But earlier in the year, in March, things looked quite different. While there were people who still thought the virus's spread was no big deal, there were others who were starting to panic. One such person was author Mikel Jollett who tweeted on March 9 the following: ${ }^{3}$

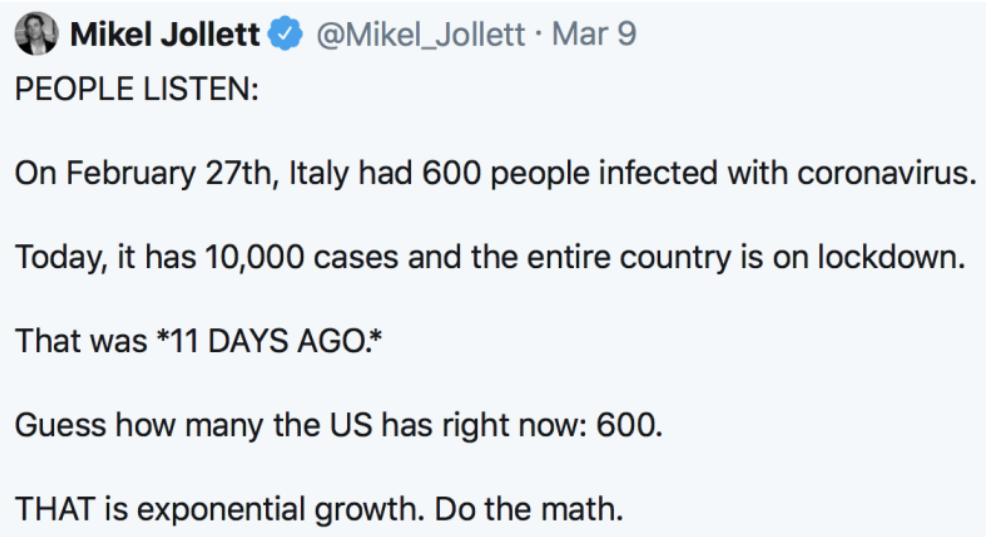

I was in the right spirit to respond "Well, to be honest, it could be linear growth with a constant of ... ok, who am I kidding? Exponential growth makes sense for modeling such processes... \#mathhelpsyousee \#dothemath". ${ }^{4}$ Of course, two data points don't prove that there is exponential growth. What one needs to add to the numbers is the decades of epidemiological modeling work that shows that exponential growth is what happens at the beginning of an unhindered epidemic.

\footnotetext{
${ }^{2}$ See https://www.cdc.gov/covid-data-tracker/index.html.

${ }^{3}$ Tweet available at https://twitter.com/Mikel_Jollett/status/1237134832070619137.

${ }^{4}$ Tweet available at https://twitter.com/GizemKaraali_/status/1237430645078413313.
} 
Going into April, we were looking at the following numbers for total US cases: 16 (by $2 / 29 / 20) ; 279$ (3/7/20); 2,234 (3/14/20); 24,583 (3/21/20); 122,653 (3/28/20). ${ }^{5}$

Besides witnessing our general lack of comprehension of exponential growth, my students and I also saw some exciting developments. In particular, we appreciated the diversity of the data visualizations that put out there to help others comprehend what was going on and what could happen next. Supported by a neat GIF, the \#FlattenTheCurve idea spread very quickly, getting its own Wikipedia article on March 12, 2020. ${ }^{6}$ A visualization of historical pandemics (LePan 2020) helped us contextualize the current crisis with what our ancestors lived through (or died with). ${ }^{7}$ We were encouraged to see a group of UCLA students taking matters (and math) into their own hands and modeling how the disease would spread in the Fall 2020 quarter if all was business as usual (Ahuja et al. 2020). ${ }^{8}$

But there was also a lot to worry about. As the CDC began to report race/ethnicity data in April, the overrepresentation of black and brown deaths in the total numbers began to stand out. ${ }^{9}$ By late April, we already knew that black and brown and indigenous people were dying at much higher rates (Hlavinka 2020; Thebault et al. 2020). It is still not clear to what extent underlying disparities in health care access and other socioeconomic parameters explain these differences, but the construct of systemic racism came to the foreground for more than a few people. The protests of various vocal groups and TV pundits against stay-at-home edicts around the country also began to get louder around the same time. Correlation does not imply causation, my students were taught to recite, but as the XKCD strip on correlation tells us in the mouseover text, "[c]orrelation doesn't imply causation, but it does waggle its eyebrows suggestively and gesture furtively while mouthing 'look over there." 10 Fitting well into the narrative arc, the next few weeks saw political tensions building up, and today in June, we see vast segments of the American society out on the streets chanting "Black Lives Matter."11

\footnotetext{
${ }^{5}$ Total Number of COVID-19 Cases, by Date Reported: https://www.cdc.gov/coronavirus/2019ncov/cases-updates/previouscases.html

${ }^{6}$ https://en.wikipedia.org/wiki/Flattening the curve

7 See https://www.visualcapitalist.com/history-of-pandemics-deadliest/. See also Joel Best's perspective piece in this issue of Numeracy (Best 2020) for historical connections and other comparative discussions contextualizing this pandemic. Best's piece is well worth reading because he also re-emphasizes the social construction of numbers and knowledge.

${ }^{8}$ See Charles Connor's article in this issue of Numeracy (Connor 2020) for another set of teaching models in the days of COVID-19.

${ }^{9} \mathrm{https}: / / \mathrm{www} . \mathrm{cdc} . \mathrm{gov} / \mathrm{mmwr} /$ volumes/69/wr/mm6915e3.htm

${ }^{10}$ https://xkcd.com/552/

11 The protests were first and foremost in response to the May 25 killing of George Floyd, an African American man, by a Minneapolis police officer who put his body weight through his knee on Floyd's neck for almost nine minutes until Floyd stopped moving. See https://en.wikipedia.org/wiki/Killing_of_George_Floyd.
} 
The pandemic brought into clear view dysfunctions of the status quo. The public's lack of expertise in handling quantitative data and models is only matched by the lack thereof among our political class. The experts we look to for help and advice, that is, if we are the sort who still looks to experts for help and advice, have often been cautious, offering us a variety of models, and encouraging patience with nuance and uncertainty. Andy Slavitt, who describes himself as an "Ex-Obama health care head" on his Twitter page, described the humble stance that scientists try to uphold: "We all have to admit the possibility that we may be-and probably are-wrong about at least some of what we believe." 12 As Cathy O'Neill writes, those in the know are very much aware of the limits of their trade: "[B]eing a skeptical data scientist means not trusting the data whatsoever. The best we can do is use the data and our real world knowledge to ballpark what might actually be happening. We will never know the true numbers." ${ }^{13}$ More recently, she writes, "Don't get me wrong: Watching the official data is not a complete waste of time and attention. The numbers can give some sense of what's happening - as long as we recognize their flaws" (O’Neill 2020).

This level of uncertainty is understood and accepted by people who are used to working with data, but for the rest, it is difficult to handle. Furthermore, most people are not used to seeing math used predictively. ${ }^{14}$ Keith Devlin (2020) writes, "[t]o most people, this is all very unfamiliar territory." At the same time, it is true that:

... for all the uncertainties and lack of good data, there is no doubt the kinds of graphs these models produce ... are extremely useful. In fact, they are the best tool we have available to enable us to see what would otherwise be invisible: the growth and spread of the virus in the society we are part of. Indeed, they are the only tool we have to do that. They are society's one pair of eyes as we manage this crisis.

But most people read math as they were taught in school: it is true, it reflects reality, there is always one correct answer, and so on. Devlin continues:

This use of mathematics is unfamiliar to most people, which is why they tend to interpret all those graphs and charts as statements of fact. But that incorrect assumption can become problematic, and potentially dangerous, when they note that the reality they are experiencing, and the actual facts that are emerging, do not match what they remember from the last graph they saw. What makes that dangerous is that they may then dismiss the model and its graphs altogether.

We have seen this before. Remember when everybody decided that polls never work because, in 2016, the presidential candidate who was given a $28.6 \%$ chance

\footnotetext{
12 https://twitter.com/ASlavitt/status/1261500248985346049

13 https://mathbabe.org/2020/03/30/comments-on-covid-19/

14 Though not everyone is used to the predictive power of mathematical models, Nathan Grawe's book review (Grawe 2020) in this issue of Numeracy reminds us that experts have been using mathematical modeling beyond just description for a long time.
} 
actually won? ${ }^{15}$ Especially when models don't say what we want to hear, there seems to be a tendency to reject the whole enterprise of predictive modeling. As Devlin wraps up his piece, he writes, "But if we do that, we are flying blind into a raging storm. Far better then to stick with the fogged and blurred-focus glasses the models provide to see the terrain ahead" (2020). I believe one of the goals of a good QL education should be to develop in our students just these habits of mind: be aware of possible issues with data and models, ask questions about sources and underlying assumptions, but also consider what different models are telling you as you make decisions. ${ }^{16}$

Today, as COVID-19 has tentatively moved to the background in the American consciousness while \#BlackLivesMatter protests have taken center stage, QL is once again an essential tool for survival. It is important to note that the virus is not necessarily gone, and that large gatherings still have the potential to become superspreader events. One positive sign is that many protestors are wearing face masks; on the other hand, physical distancing is by definition going to be elusive in a mass protest. Furthermore, in several instances, police responded to protestors with tear gas, which itself might enhance the threat of the pandemic (Tufekci 2020).

Some hope that warm weather will help; others think outdoor events are less dangerous. A handful of outspoken public health professionals are also pointing out that the protests are bringing much needed attention to racism, a most deadly problem in the United States, and one whose impact on the pandemic might be more direct than most might imagine. ${ }^{17}$ Most of the protestors are young, and data suggest that younger people are less in danger of suffering a tough case of this disease. ${ }^{18}$ However some young people do die from the disease or any of its myriad complications, and others might simply pass it on to more vulnerable people.

Where does QL come in? Consider the question, "Should I protest?" Individuals, protestors and non-protesting supporters alike, are making decisions on this question with a large amount of data in their hands. Many protestors will likely accept that COVID-19 still poses a serious danger, probably not only to themselves but also to others around them who might be more vulnerable. But they also believe that systemic racism is itself a public health emergency, one that kills many black people and hurts countless others in all sorts of ways. ${ }^{19}$ Some weigh

\footnotetext{
${ }^{15} \mathrm{https}$ ://projects.fivethirtyeight.com/2016-election-forecast/

${ }^{16}$ Another familiar statement of this same sentiment could be "Trust but verify." No wonder Ethan Bolker and Maura Mast titled their QL text "Common Sense Mathematics!"

${ }^{17}$ See "Open letter advocating for an anti-racist public health response to demonstrations against systemic injustice occurring during the COVID-19 pandemic," available at https://drive.google.com/file/d/1Jyfn4Wd2i6bRi12ePghMHtX3ys1b7K1A/view.

${ }^{18} \mathrm{See}$, for example, https://data.cdc.gov/NCHS/Provisional-COVID-19-Death-Counts-by-SexAge-and-S/9bhg-hcku.

${ }^{19}$ See for instance this statement from Washington State Nurses Association, "Racism is a public health emergency": https://www.wsna.org/news/2020/racism-is-a-public-health-emergency.
} 
the risks of acting and not acting, and they decide to walk out the door. Others look at similar data and reach a different conclusion.

There isn't a QL-kosher answer to this question that is one-size-fits-all. Each and every person makes their own decision. Our goal as promoters of QL should be to help people make their decisions with open eyes, understanding the repercussions, which in this case are life-or-death serious, on both sides. Here as in most other contexts, QL is flexible and open-ended. It only guides one in clear-eyed deliberation, not spitting out a canned answer but instead offering support as needed. We all know that the most important human questions are not mainly about the numbers; even though we often try to assign numerical values to things (like a human life, for example; see Rogers [2020]), we know in the end that there is a human judgment element that goes beyond the numbers and the calculations. All in all, we make life-or-death decisions with a range of guiding principles. Our goal should be to ensure that folks do take QL along, too, knowing full well that it will serve as a guide on the side as opposed to performing as the sage-on-the-stage. ${ }^{20}$

Finally, I want to share with you the following quote from "some sort of processed beef": ${ }^{21}$

... critical thinking is not a singular skill. it's a constant state of metacognition, measuring evidence, and recognizing when to defer to experts. it's analyzing this tweet's substance, motivations, credibility, and source, not just reading it. ${ }^{22}$

As someone who has spent significant time thinking about definitions of QL (cf. Karaali et al. 2016), I think this is as good a description of QL as of critical thinking. The past few weeks prove once again its relevance and urgency.

\section{Acknowledgments}

I am grateful to Len Vacher and Nathan Grawe for inviting me to join the editorial team at Numeracy and giving me the opportunity to write this essay.

\section{References}

Ahuja, Radhika, Charlotte Huang, Sydney Kovach, and Laurel Woods. 2020. "Modeling the Spread of COVID-19 in UCLA Classrooms." Published online at The Stack: Data and tech blog from the Daily Bruin on May 12, retrieved from https://stack.dailybruin.com/2020/05/12/covid-model/. Ancker, Jessica. 2020. "The COVID-19 Pandemic and the Power of Numbers." Numeracy 13(2): Article 2. https://doi.org/10.5038/1936-4660.13.2.1358.

\footnotetext{
${ }^{20}$ Please forgive my insertion of these pedagogical metaphors here. I think they fit.

${ }^{21}$ Quoted phrase is from https://twitter.com/callin_bull/status/1253588491763544064.

${ }^{22}$ https://twitter.com/steak_umm/status/1253514561128402944
} 
Bennett, Jeffrey O. 2012. Math for Life: Crucial Ideas You Didn't Learn in School. Greenwood Village, CO: Roberts and Company Publishers.

Best, Joel. 2020. "COVID-19 and Numeracy: How about Them Numbers?" Numeracy 13(2): Article 4. https://doi.org/10.5038/1936-4660.13.2.1361.

Connor, Charles. 2020. "Factors in the Probability of COVID-19 Transmission in University Classrooms." Numeracy 13(2): Article 7.

Devlin, Keith. 2020. "The Graph That Stopped The World." Published online at MAA MathValues blog on May 1, retrieved from https://www.mathvalues.org/masterblog/the-graph-that-stopped-the-world.

Grabiner, Judith V. 2011. "How to Teach Your Own Liberal Arts Mathematics Course." Journal of Humanistic Mathematics 1(1): 101-118. https://doi.org/10.5642/jhummath.201101.08.

Grawe, Nathan. 2020. "From R0 to the Herd: A Review of The Rules of Contagion, by Adam Kucharski." Numeracy 13(2): Article 10. https://doi.org/10.5038/1936-4660.13.2.1363

Hlavinka, Elizabeth. 2020. "COVID-19 Further Strains Care Disparities Among Native Americans." Published online at MedPage Today on May 21, retrieved from https://www.medpagetoday.com/infectiousdisease/covid19/86633.

Karaali, Gizem, Edwin Villafane-Hernandez, and Jeremy Taylor. 2016. "What's in a Name? A Critical Review of Definitions of Quantitative Literacy, Numeracy, and Quantitative Reasoning." Numeracy 9(1): Article 2. https://doi.org/10.5038/1936-4660.9.1.2.

LePan, Nicholas. 2020. "Visualising the History of Pandemics." Published online at Visual Capitalist on March 14, retrieved from https://www.visualcapitalist.com/history-of-pandemics-deadliest/.

Madison, Bernard L., and Lynn Arthur Steen. 2008. "Evolution of Numeracy and the National Numeracy Network." Numeracy 1(1): Article 2. https://doi.org/10.5038/1936-4660.1.1.2.

Mellow, Gail O. 2018. "Quantitative Literacy: Now More Than Ever.” Numeracy 11(2): Article 1. https://doi.org/10.5038/1936-4660.11.2.1.

O’Neill, Cathy. 2020. "10 Reasons to Doubt the Covid-19 Data." Published online at Bloomberg Opinion on April 13, retrieved from https://www.bloomberg.com/amp/opinion/articles/2020-04-13/ten-reasonsto-doubt-the-covid-19-data

Piercey, Victor. 2020. "Quantitative Literacy in the Time of COVID-19." Published online at Dana Center Blog \& News on June 8, retrieved from https://www.utdanacenter.org/blog/quantitative-literacy-time-covid-19

Rogers, Adam. 2020. "How Much Is a Human Life Actually Worth?” Published online at Wired on May 11, retrieved from https://www.wired.com/story/how-much-is-human-life-worth-in-dollars/ 
Thebault, R., A. Ba Tran, and V. Williams. 2020. "The Coronavirus Is Infecting and Killing Black Americans at an Alarmingly High Rate." Washington Post. April 7, 2020. Available at:

https://www.washingtonpost.com/nation/2020/04/07/coronavirus-isinfecting-killing-black-americans-an-alarmingly-high-rate-post-analysisshows/

Tufekci, Zeynep. 2020. "I Can't Breathe: Braving Tear Gas in a Pandemic." Published online at The Atlantic on June 4, retrieved from https://www.theatlantic.com/health/archive/2020/06/i-cant-breathe-usingtear-gas-during-pandemic/612673/. 